\title{
Canada releases national dementia plan
}

$\mathrm{C}$ anada finally has a dementia plan. Federal Health Minister Rona Ambrose announced the new National Dementia Research and Prevention Plan at a Sept. 11, 2014, meeting of leading researchers and industry experts in Ottawa. Previously, Canada was the only G7 nation without a national strategy for tackling the disease and faced criticism for dragging its feet on the file.

The new plan outlines investments, partnerships and initiatives already underway to stimulate dementia research and reduce the burden on families. These include two new efforts: a $\$ 31.5$ million initiative to support collaborative dementia research across 20 expert teams and an awareness program to foster "dementia-friendly" communities.

"We are committed with our G7 counterparts to find a cure by 2025," Ambrose told delegates to the CanadaFrance Global Dementia Legacy Event. "This will mean a lot of work, not only in the research community, but also with the provinces and territories to take the research and turn it into action on the ground."

Unlike other national dementia strategies, Canada's plan does not include long-term goals for coordinating care or building health system capacity to accommodate the rising tide of new patients.

Those issues are still being hashed out with the provinces, Ambrose told reporters. She hesitated to describe the plan as a "national dementia strategy."

"I'm very optimistic that we'll continue further down the road to see a more full-fledged plan, but this plan incorporates all the pieces that we need," said Ambrose. "At the end of the day, it's what the provinces and territories agree to call it."

By federal estimates, some 747000 Canadians were living with Alzheimer

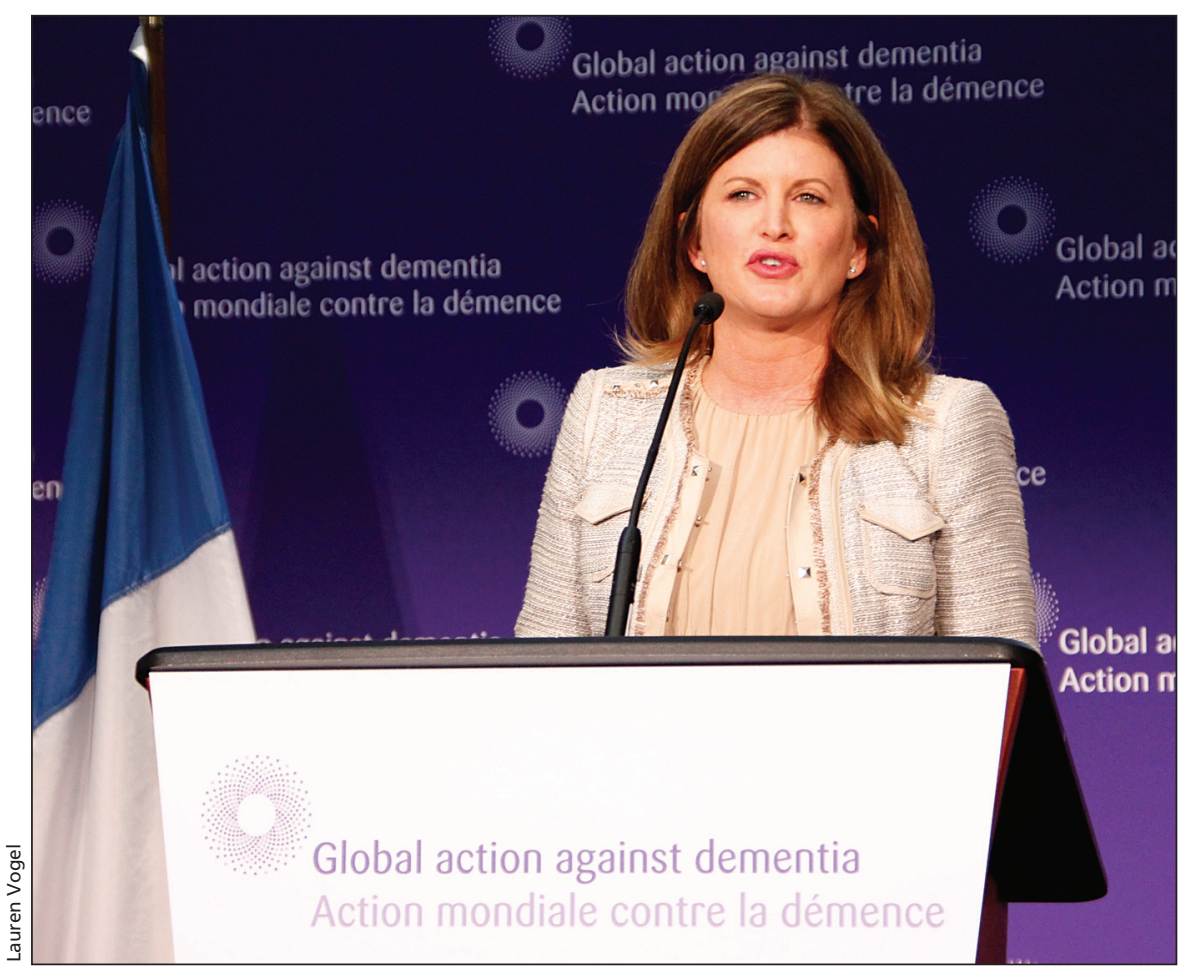

Canada cannot ignore the threat dementia poses to our health system when it comes to cost and care, Health Minister Rona Ambrose urged at a Sept. 11 event in Ottawa.

disease or other dementias in 2011. That number is expected to skyrocket to 1.4 million over the next two decades, costing the economy almost $\$ 300$ billion per year.

Ambrose also announced the results of a four-year, \$15-million National Population Health Study of Neurological Conditions - the largest of its kind conducted in Canada. The study showed that Canadians with neurological conditions, including Alzheimer disease and other dementias, require more frequent and intensive care than others. For example, they visit physicians 1.45.6 times more frequently. People with neurological conditions also make up more than half of all continuing-care patients.

"We may need to build more longterm care facilities, or incorporate more care for Alzheimer's disease into those facilities, or potentially move resources around in home care - that's all for the provincial health ministers to discuss," said Ambrose. As for the federal role: "We can work very well ... providing the information they need through research."

Some 200 delegates from G7 countries and major international organizations attended the Canada-France Dementia Legacy Event. It's the second in a series of four events stemming from the Summit on Dementia held in London, England, in December 2013. Japan and the United States will host the next events in fall 2014 and winter 2015, respectively. - Lauren Vogel, CMAJ

CMAJ 2014. DOI:10.1503/cmaj.109-4902 